\title{
Future Changes in Precipitation Extremes Associated with Tropical Cyclones Projected by Large-Ensemble Simulations
}

\author{
Akio KITOH \\ Japan Meteorological Business Support Center, Tsukuba, Japan \\ Meteorological Research Institute, Tsukuba, Japan \\ and \\ Hirokazu ENDO \\ Meteorological Research Institute, Tsukuba, Japan \\ (Manuscript received 20 June 2018, in final form 15 October 2018)
}

\begin{abstract}
Future changes in precipitation extremes and role of tropical cyclones are investigated through a large ensemble experiment, considering 6,000 years for the present and 5,400 years under $+4 \mathrm{~K}$ warming, using a $60-\mathrm{km}$ mesh Meteorological Research Institute atmospheric general circulation model version 3.2. As in the previous findings of the authors, the annual maximum 1-day precipitation total (Rx1d) is projected to increase in the warmer world in the future almost globally, except in the western North Pacific where a projected decrease of tropical cyclone frequency results in only small change or even reduction of Rxld. Furthermore, a large ensemble size enables us to investigate the changes in the tails of the Rx1d distribution. It is found that 90- and 99-percentile values of the Rxld associated with tropical cyclones will increase in a region extending from Hawaii to the south of Japan. In this region, the interannual variability of the Rxld associated with tropical cyclones is also projected to increase, implying an increasing risk of rare heavier rainfall events because of global warming.
\end{abstract}

Keywords precipitation extremes; tropical cyclone; global warming; AGCM; large ensemble

Citation Kitoh, A., and H. Endo, 2019: Future changes in precipitation extremes associated with tropical cyclones projected by large-ensemble simulations. J. Meteor. Soc. Japan, 97, 141-152, doi:10.2151/jmsj.2019-007.

\section{Introduction}

Global warming leads to changes in various aspects of extreme weather and climate events. It is assessed that the frequency of heavy precipitation will likely increase in the 21 st century over many areas of the world (IPCC 2012). Heavy precipitation associated

Corresponding author: Akio Kitoh, Japan Meteorological Business Support Center, 1-1 Nagamine, Tsukuba, Ibaraki 305-0052, Japan

E-mail: kitoh@jmbsc.or.jp

J-stage Advance Published Date: 29 October 2018 with tropical cyclones (TCs) is also likely to increase because of continuous warming (IPCC 2012).

There exist modeling activities to project future climate using global atmosphere-ocean coupled general circulation models (AOGCM) such as the Coupled Model Intercomparison Project Phase 5 (CMIP5, Taylor et al. 2012). It is projected that the change rate of heavy precipitation amounts will become more than that of mean precipitation (Tebaldi et al. 2006; Sillmann et al. 2013b). The CMIP5 models reasonably reproduce present-day spatial distributions of various precipitation indices but the magnitude of precipitation 
extremes is underestimated (Sillmann et al. 2013a). Hence, a high-resolution model is needed to reproduce weather and climate extremes and project their future changes (Kitoh et al. 2016). In low-latitudes, TCs have important contributions to heavy precipitation (e.g., Kamahori 2012). Therefore, models should reasonably reproduce TCs and its corresponding precipitation to properly project future climate changes.

We have been using the high-resolution global atmospheric general circulation model (AGCM) version 3.2 developed at the Meteorological Research Institute (MRI-AGCM3.2; Mizuta et al. 2012) to project future changes in weather and climate extremes such as TCs, heavy precipitation, and strong winds. Our experimental strategy is described by Kitoh et al. (2009). The present-day climate is forced by the interannually varying observed monthly sea surface temperature (SST). Meanwhile, the future climate is forced by the SST where the projected future changes of monthly mean SST climatology are added to the present-day SST using AOGCMs in CMIP5 or CMIP3 experiments.

Kitoh and Endo (2016a) used four-member ensemble simulations with different SST patterns using the 20-km mesh MRI-AGCM3.2 at the end of the 21st century (2075-2099) under the RCP8.5 scenario. They found that heavy precipitation increases in all regional domains over land, even where mean precipitation decreases. Using the same data, Kitoh and Endo (2016b) analysed the annual maximum 1-day precipitation total (Rx1d) and its relation with TCs. The Rx1d is projected to increase in the future, with larger increase in regions where Rxld is climatologically high. However, the exception is the western North Pacific where only a small change or even a reduction of the $\mathrm{Rx} 1 \mathrm{~d}$ is projected. This is mainly related to a decrease of the TC frequency in this region. Meanwhile, the interannual variability of Rx1d in the western tropical Pacific increases associated with El Niño (note that in the experiment the same interannual variability in SST is given for future climate as that given in the present-day climate). However, the sample size of the experiment is small and the statistical significance of the projected changes is low. In order to discuss the statistical significance of Rxld changes, a large ensemble size is needed.

As ensemble size should be limited with the $20-\mathrm{km}$ model owing to computational cost, we made large ensemble simulations using a $60-\mathrm{km}$ model as called "Database for Policy Decision Making for Future Climate Change" (d4PDF) (Mizuta et al. 2017). Although the $60-\mathrm{km}$ model is limited in terms of quantitatively reproduce TC intensity compared with the $20-\mathrm{km}$ model, the spatial pattern and amount of precipitation extremes are reasonably simulated (Endo et al. 2012).

Mizuta et al. (2017) described the experimental details and preliminary findings of d4PDF. Yoshida et al. (2017) investigated the future changes in a global TC activity. They showed an increase of very intense (i.e., categories 4 and 5) TC occurrence in the region to the south of Japan, and a global mean increase of lifetime maximum surface wind speeds and precipitation. Endo et al. (2017) investigated the precipitation extremes in East Asia and showed that Rx1d robustly increases throughout East Asia. They also showed that spatial patterns of future SST changes ( $\triangle \mathrm{SSTs})$ affect Rx1d quantitatively over oceanic regions in East Asia including Japan, Korea and coastal China, through the modulation of the TC activity.

In this paper, future changes of the Rx1d and TCassociated Rxld are analyzed using the large ensemble d4PDF data. Not only the mean but also the tails of the distribution are investigated. The model and experimental setups are described in Section 2. Model performance to reproduce Rx1d and its relation with $\mathrm{TC}$ in the present-day climate are examined in Section 3. Section 4 investigates their future changes at the $4 \mathrm{~K}$ warmer world corresponding to the end of the 21 st century. Summary and discussions are given in Section 5.

\section{Model and experiment}

\subsection{MRI-AGCM}

The model used is a $60-\mathrm{km}$ mesh version of the MRI-AGCM3.2 (Mizuta et al. 2012), which has 64 layers in the vertical with a top at $0.01 \mathrm{hPa}$. A massflux-type cumulus parameterization scheme (Yoshimura et al. 2015) is used. This model has been used to investigate future changes of precipitation (Endo et al. 2012; Kusunoki and Mizuta 2013; Kusunoki 2017) and TC (Murakami et al. 2012b; Sugi and Yoshimura 2012).

\subsection{Experiment: $d 4 P D F$}

The experimental design and several preliminary results of the "Database for Policy Decision Making for Future Climate Change (d4PDF)" are shown by Mizuta et al. (2017), Matsueda and Endo (2017), Endo et al. (2017), and Yoshida et al. (2017).

The present-day climate experiment is conducted for the period 1951-2010, in which the observed inter-annually varying monthly-mean SST and sea ice concentration (COBE-SST2) (Hirahara et al. 2014) are used as the lower boundary conditions. A 100-member 
ensemble simulation is conducted with different atmospheric initial conditions as well as small perturbations in SSTs ( $\delta$ SSTs). Here the typical magnitude of $\delta \mathrm{SST}$ is set to be below the observed uncertainty in a monthly time scale, which is $0.2 \mathrm{~K}$, for example, in the western tropical Pacific.

For the future climate experiment, a 60 -year integration with 90 members is conducted corresponding to the conditions in the 2090s under the RCP 8.5 scenario. The prescribed global mean surface air temperature (SAT) in the future climate is $4.1 \mathrm{~K}$ warmer than the pre-Industrial level or $3.6 \mathrm{~K}$ warmer than the present climate (1951-2010). The future SST is the sum of CMIP5 AOGCM-projected SST anomalies $(\triangle \mathrm{SSTs})$ and the observed SST after the removal of the long-term trend component. To cover the uncertainty of future SST projections, six different $\triangle$ SSTs (i.e., CCSM4, GFDL-CM3, HadGEM2-AO, MIROC5, MPI-ESM-MR, and MRI-CGCM3, denoted by CC, GF, HI, MP, MP, and MR SST, respectively) are selected based on cluster analysis of tropical $\triangle$ SSTs. The $\Delta$ SSTs are normalized to give a global mean SAT $4 \mathrm{~K}$ warmer than the pre-Industrial level. For each of the six $\Delta$ SSTs, 15 -member ensemble runs are conducted using different atmospheric initial conditions and different $\delta$ SSTs (i.e., 90 members in total). In total, we used 6,000-year data for the present climate, and 5,400 -year data for the future climate.

\subsection{Observation data}

In order to investigate the precipitation extremes associated with TCs, we use the daily precipitation data. For the observed precipitation data, we use Tropical Rainfall Measuring Mission (TRMM) 3B42 product in version 6 (Huffman et al. 2007), Climate Prediction Center morphing method (CMORPH) (Joyce et al. 2004), Global Satellite Mapping of Precipitation (GSMaP) (Ushio et al. 2009), Precipitation Estimation from Remotely Sensed Information Using Artificial Neural Networks (PERSIANN) (Sorooshian et al. 2000), and Global Precipitation Climatology Project with a 1-degree by 1-degree grid (GPCP-1dd) (Huffman and Bolvin 2009). The spatial resolution of the data is 0.25 degree for the TRMM 3B42, CMORPH, GSMaP, and PERSIANN, while it is 1.0 degree for GPCP-1dd. For the observed TC tracks, we use the International Best Track Archive for Climate Stewardship (IBTrACS) v03r06 (Knapp et al. 2010). This TC track dataset used in this study covers the 15 -year period of 1998-2012.

\section{Present-day Rx1d and its relation with TCs}

The $60-\mathrm{km}$ mesh version of the MRI-AGCM3.2 shows good skill in simulating monsoon circulations and precipitation (Endo et al. 2012; Mizuta et al. 2017). The model successfully reproduces the pattern as well as the amount of both mean and extreme precipitation globally and regionally (Endo et al. 2012; Kusunoki 2016, 2017). The model also reproduces various characteristics of TCs such as their intensity and global distribution (Yoshida et al. 2017).

Figure 1 compares observed Rx1d and simulated Rx1d using the $60-\mathrm{km}$ mesh MRI-AGCM3.2. All the data are in the average of 10 years from 2001 to 2010. The model data are also based on one-member of the same period. The observed estimations show large Rxld in the western North Pacific, Bay of Bengal, Intertropical Convergence Zone (ITCZ) and South Pacific Convergence Zone (SPCZ). There is large uncertainty among different observation-based estimates. The areal averages of the Rxld between $50^{\circ} \mathrm{S}$ and $50^{\circ} \mathrm{N}$ are $75.4 \mathrm{~mm}$ (TRMM), $65.6 \mathrm{~mm}(\mathrm{CMORPH})$, $79.6 \mathrm{~mm}$ (GSMaP), $49.0 \mathrm{~mm}$ (PERSIANN), and 39.3 $\mathrm{mm}$ (GPCP-1dd). The uncertainty range is factor 2 from the least GPCP to the largest GSMaP. The $60-\mathrm{km}$ mesh MRI-AGCM3.2 (Fig. 1f) reproduces the observed Rx1d reasonably with an areal average amount $(58.0 \mathrm{~mm})$ within the observed uncertainty range.

Figures $2 \mathrm{a}$ and $2 \mathrm{~b}$ show the observed Rx1d and Rxld associated with TCs (Rx1d-TC) based on the TRMM 3B42 data within 1998-2012. We calculated the Rx1d-TC from daily precipitation within $500 \mathrm{~km}$ from the TC center, as precipitation around the TCs is concentrated within a 5-degree radius from the TC center (Kamahori 2012). Based on this definition, the distribution of the Rx1d-TC corresponds to that of the TCs themselves. Its magnitude is large in the western North Pacific within $10^{\circ} \mathrm{N}-25^{\circ} \mathrm{N}$ and in the eastern North Pacific off Mexico. Figure 2c shows that the distribution of the Rx1d-nTC, which is not associated with TCs, is similar to that of the Rx1d. The exception is found in the western tropical Pacific near the Philippines, where the magnitude is significantly less than that of the Rxld.

Figures $2 \mathrm{~d}-\mathrm{f}$ are simulated counterparts to Figs. $2 \mathrm{a}-\mathrm{c}$ obtained using the $60-\mathrm{km}$ mesh MRI-AGCM3.2, in an average of 6,000 years. The $60-\mathrm{km}$ mesh MRIAGCM reproduces the observed Rx1d, Rx1d-TC and Rx1d-nTC but the magnitude is slightly underestimated compared with the TRMM data. In particular, the simulated Rx1d-TC resembles the observed features in the Pacific and Indian Oceans. Simulated Rx1d- 
(a) $R \times 1 d$ TRMM

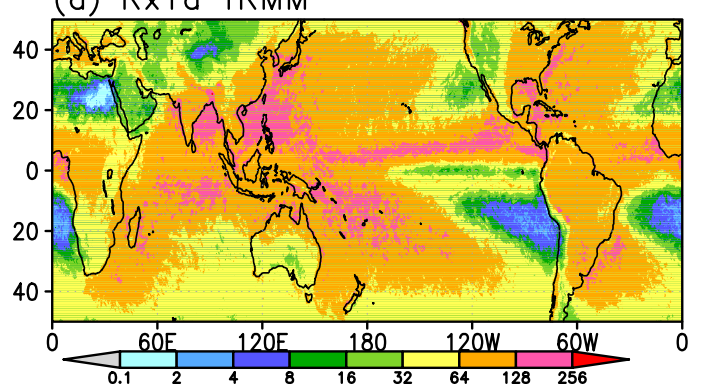

(b) $\mathrm{R} \times 1 \mathrm{~d}$ CMORPH

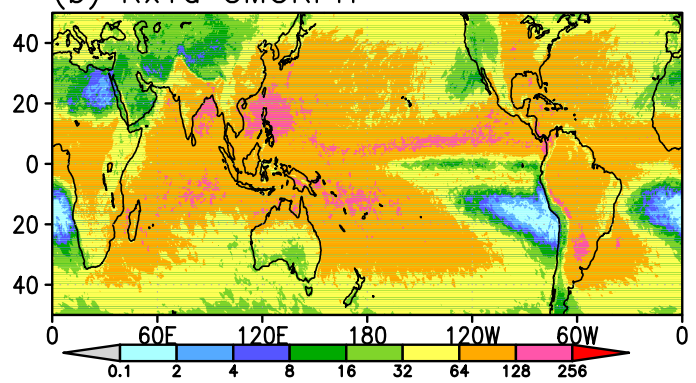

(c) Rx1d GSMaP

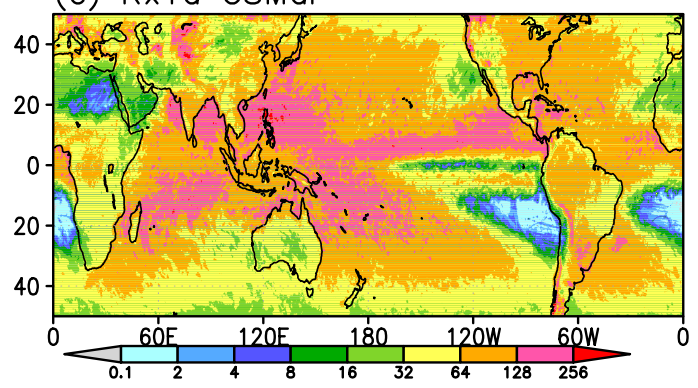

(d) Rx1d PERSIANN-CDR

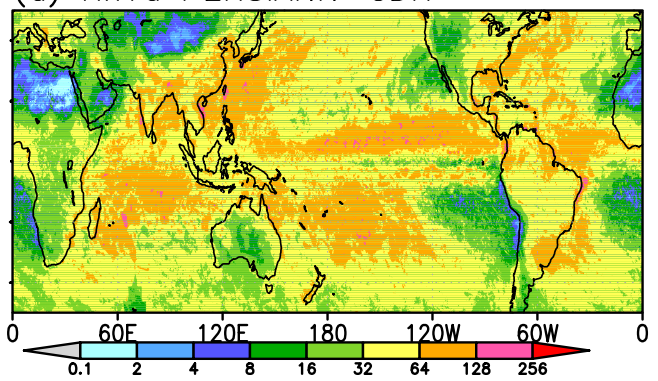

(e) $R \times 1 d$ GPCP

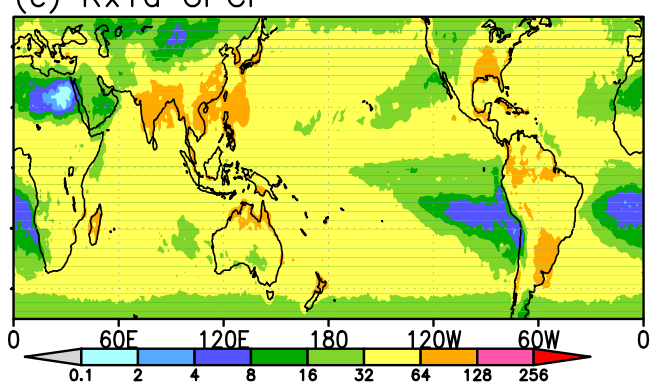

(f) $R \times 1 d$ d4PDF (mem 1)

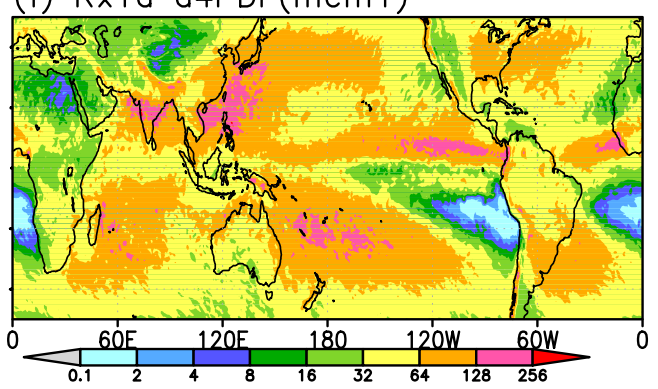

Fig. 1. Rx1d climatology estimated using (a) TRMM-3B42, (b) CMORPH, (c) GSMaP, (d) PERSIANN, and (e) GPCP-1dd for the 10-year period between 2001 and 2010. In (f), the Rx1d based on the one-member 60-km mesh MRI-AGCM3.2 corresponding to 2001-2010 is plotted. Unit is mm.

TC, however, is greatly underestimated in the North Atlantic Ocean. This failure is associated with poor TC reproducibility in the North Atlantic Ocean as noted by Murakami et al. (2012b), but the reason is not clarified. The $20-\mathrm{km}$ mesh version of MRI-AGCM 3.2 better simulates the TC frequency (Murakami et al. 2012a) and Rx1d-TC (Kitoh and Endo 2016b). It is noted that quantitative accuracy of the TRMM data is debatable (Huffman et al. 2007). For example, using the Pacific atoll and island precipitation dataset, Chen et al. (2013) showed that TRMM 3B42 tends to overestimate heavy precipitation frequency at atoll sites but underestimate it at coastal and island sites with high elevation.

\section{Future changes}

Using the 20-km mesh version of MRI-AGCM3.2, Kitoh and Endo (2016b) showed that the changes in the Rx1d in future climate generally follow the climatological pattern in Rx1d. There are large increases in the Rx1d in the central-eastern equatorial Pacific, equatorial Atlantic Ocean, and south and east of Japan and SPCZ. An exception is the western tropical Pacific, where Rxld is climatologically large but future change are small or even negative. This peculiar change is considered to be related to the changes in TC activities there (Kitoh and Endo 2016b).

Figure $3 \mathrm{a}$ shows the future changes in the median (50-percentile) value of Rx1d using the $60-\mathrm{km}$ mesh 

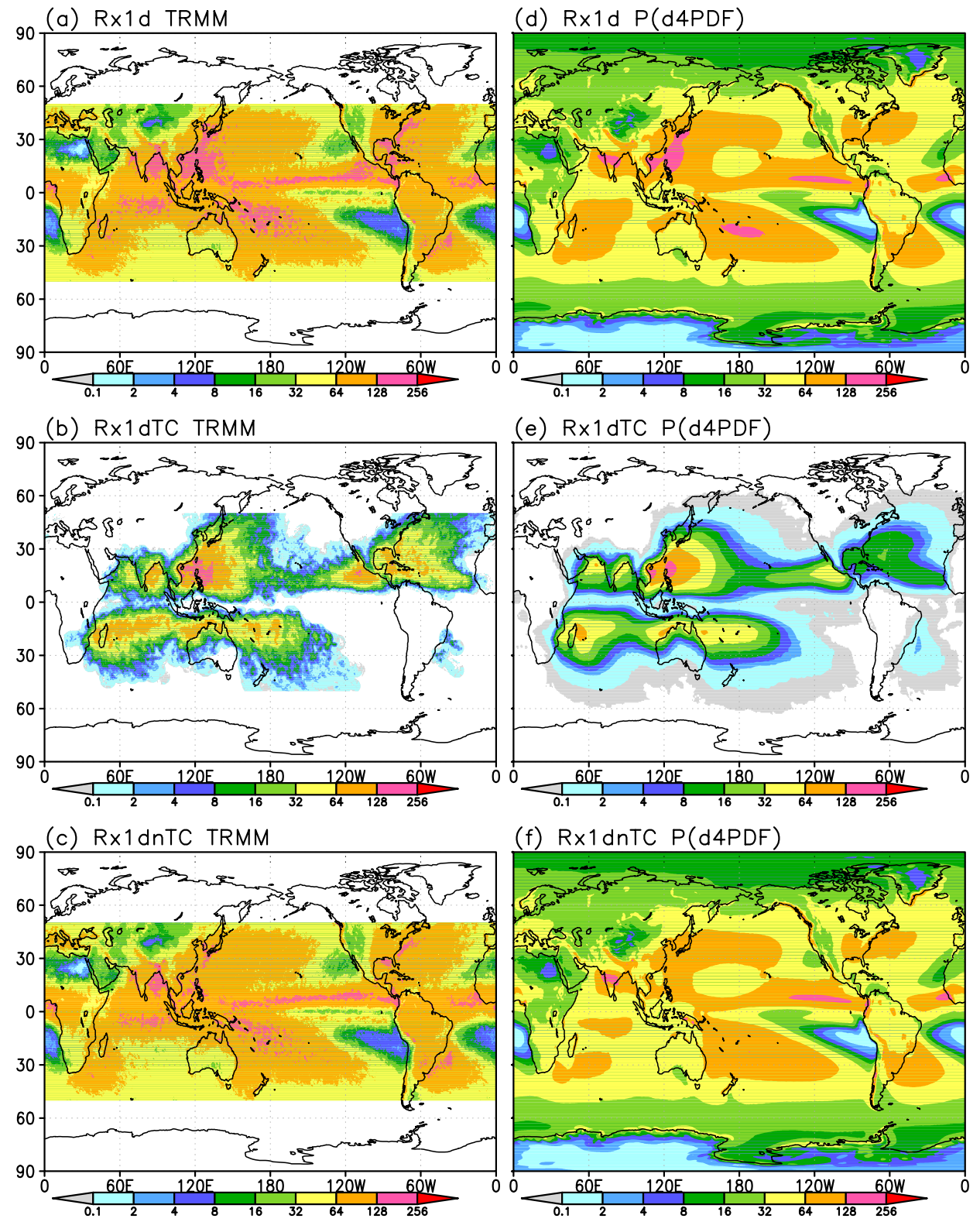

Fig. 2. (a, b, c) Observed and (d, e, f) simulated climatology of (a, d) Rx1d, (b, e) TC-associated Rx1d, and (c, f) non-TC-associated Rx1d. Unit is $\mathrm{mm}$.

MRI-AGCM3.2. Most parts of the world will experience larger Rxld in a warmer world. However, being consistent with the $20-\mathrm{km}$ model results, there are some regions where Rxld is projected to decrease in the future warmer world, including the western tropical Pacific around the Philippines between the equator and $20^{\circ} \mathrm{N}$. This is mainly due to a decrease in the Rx1d-TC (Fig. 3d) brought by the reductions in TC frequency.
The SST change pattern can affect future precipitation changes in the tropics (Xie et al. 2010; Ose and Arakawa 2011). In this experiment, as described in Section $2 b$, six different geographical patterns of $\Delta$ SSTs are used to cover the uncertainty of most parts of the CMIP5 models. Changes in Rx1d, Rx1d-TC and TC frequency in each of the six sub-ensembles are shown in Fig. 4. Spatial patterns are similar to each other but with some differences in magnitude. 

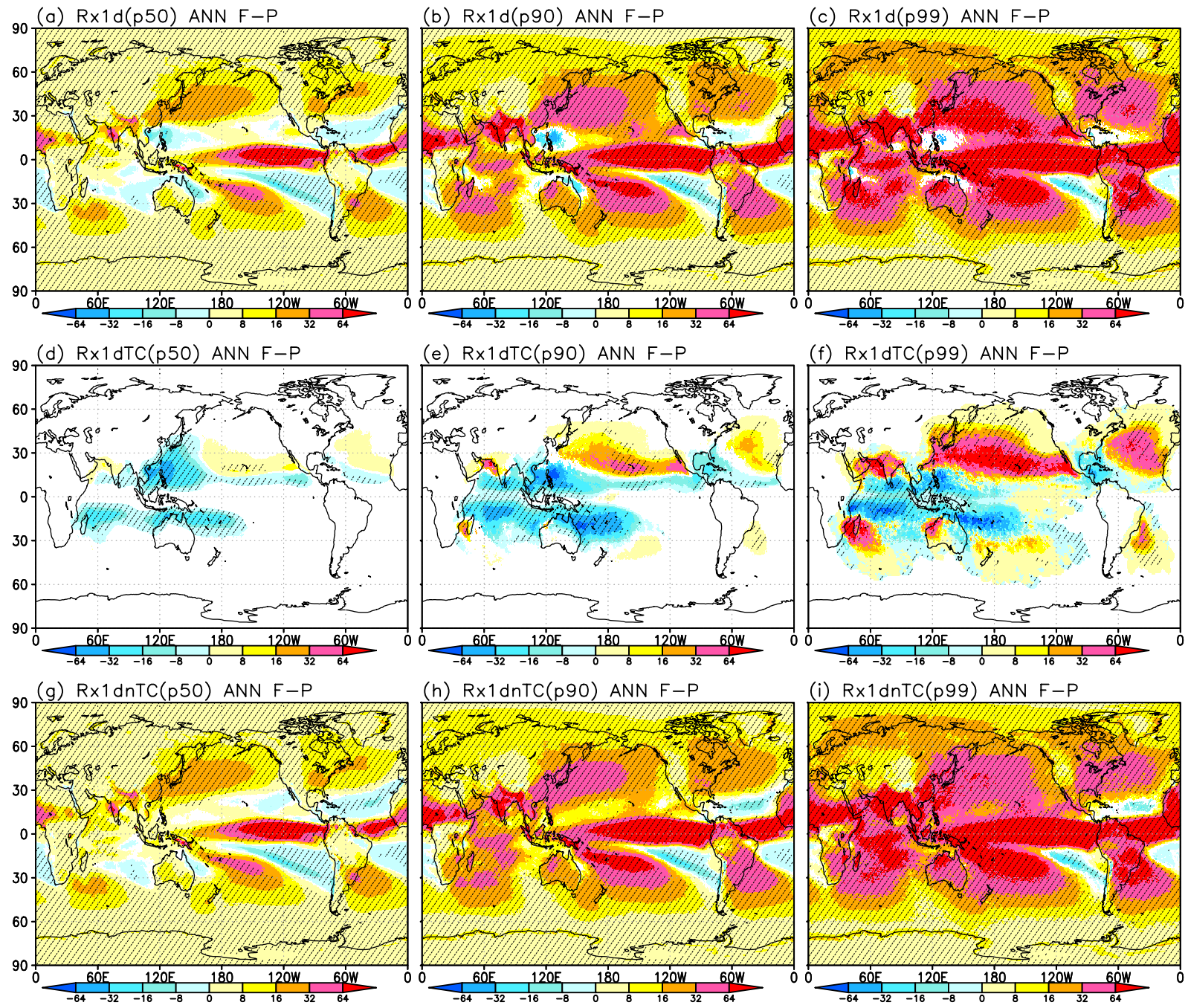

Fig. 3. Projected future changes (future minus present) (a, b, c) Rxld, (d, e, f) Rx1d-TC, and (g, h, i) Rx1d-nTC at (a, d, g) 50-, (b, e, h) 90-, and (c, f, i) 99-percentile thresholds. Unit is mm. Statistically significant changes at $95 \%$ are color shaded. The hatches denote the areas where all six members of different $\Delta$ SST pattern experiments have the same sign.

Prescribed SST anomalies in the equatorial Pacific should be the main reason of difference among subensembles. For example, El Niño-like $\triangle$ SSTs (HA, MP, and MR SST) result in an intensification of mean and extreme precipitation in the central and eastern equatorial Pacific regions (Mizuta et al. 2017). All six experiments with different SST patterns consistently show a decrease in Rx1d-TC around the Philippines, although its magnitude varies greatly between -0.7 $\mathrm{mm}$ (MR SST) and $-3.4 \mathrm{~mm}$ (MI SST). The subensemble with a large decrease in the TC frequency in the western tropical Pacific (MI SST) leads to a large decrease in the Rx1d-TC and then Rx1d in the area. Similarly, the sub-ensemble with an increase in the TC frequency around Hawaii (HA SST) leads to an increase in the Rx1d-TC and then Rx1d in the area. Therefore, there is regionally non-negligible effect of different SST pattern changes on future Rx1d changes.

The result in Fig. 3a is based on the median values of Rx1d within 6,000 and 5,400 years of the present and future simulations, respectively, where Rx1d is defined per year. An extremely large Rx1d may increase more than the mean Rx1d in the future. Figures $3 \mathrm{~b}$ and $3 \mathrm{c}$ show the future changes in the 90 - 

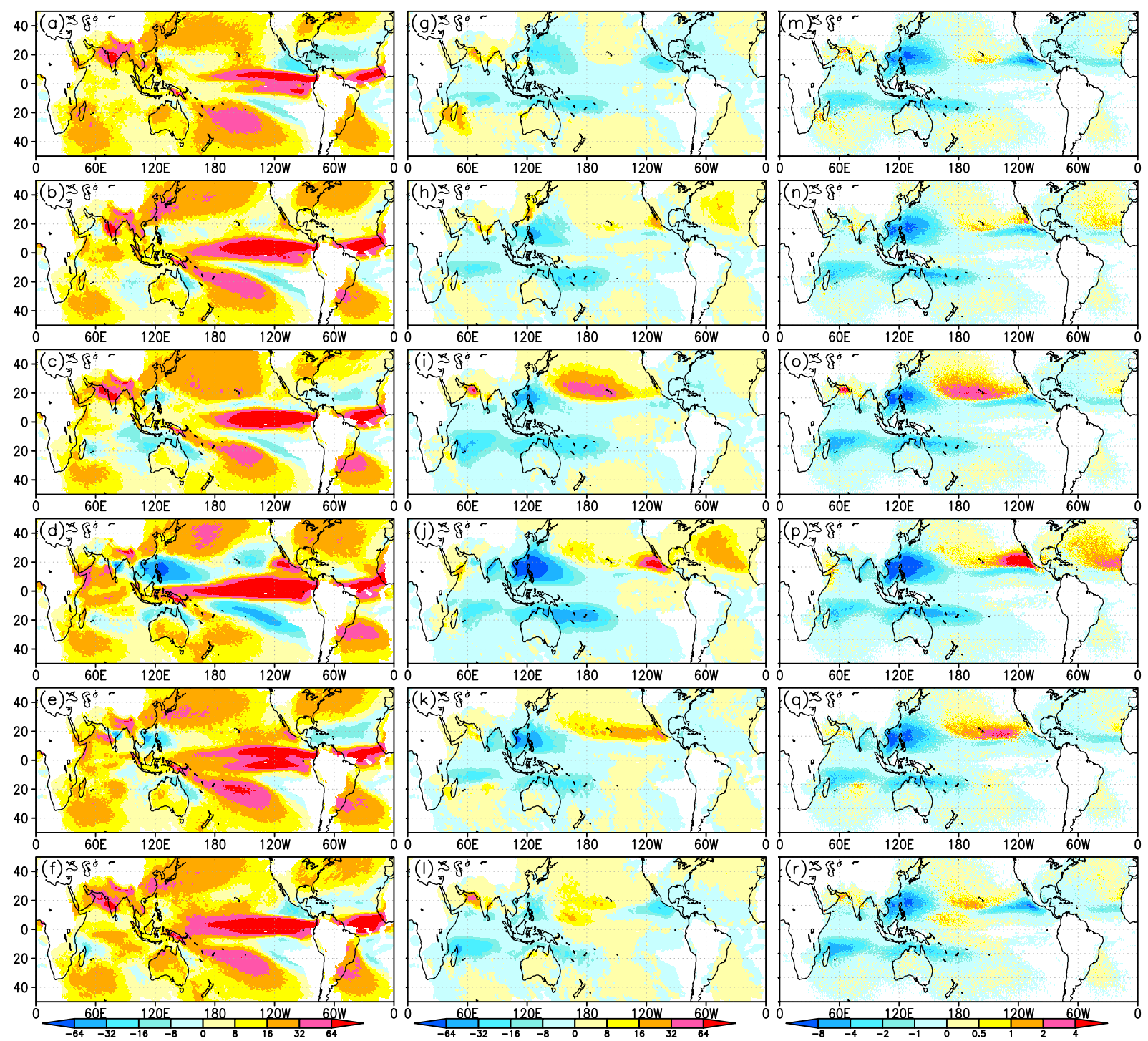

Fig. 4. Future changes in (a-f) Rxld, (g-l) Rxld-TC, and (m-r) TC frequency. (a, g, m) CC, (b, h, n) GP, (c, i, o) HA, (d, j, p) MI, (e, k, q) MP, and (f, $1, r)$ MR SST experiments. Units are mm for Rx1d and Rx1d-TC, and number per 60 years in each grid for the TC frequency.

and 99-percentile values of the Rx1d. Their changes in global mean values are +26.4 and $+45.2 \mathrm{~mm}$, respectively, which are much larger than $+10.2 \mathrm{~mm}$ of the change in the 50-percentile value. As expected, the absolute change in high extremes is larger than that in the mean or median, and the changing ratio is also calculated. The global mean ratio of the changes relative to the present-day value is $+27.5 \%,+34.2 \%$, and $+39.6 \%$ in the 50-, 90-, and 99-percentile values of $\mathrm{Rx} 1 \mathrm{~d}$, respectively. Larger increasing rate for higher percentiles owing to global warming is consistent with previous findings (O'Gorman 2012; Scoccimarro et al. 2013; Sillmann et al. 2013b).

The areal coverage with positive or negative Rx1d changes differs at different threshold percentiles. The area with positive changes in the 50-, 90-, and 99-percentile values of Rx1d is $84.6 \%, 93.2 \%$, and $96.3 \%$, respectively worldwide. This result indicates that more and more regions will experience extremely intense precipitation in the future. Even where the mean/median Rxld is projected to decrease, the magnitude of rare events, such as those occurring once 
in 10 years or once in 100 years, may increase in the future warmer world.

Figures $3 \mathrm{~d}-\mathrm{f}$ show the future changes in the 50 -, 90-, and 99-percentile values of Rx1d-TC. The 50percentile (median) value of Rx1d-TC is projected to decrease almost worldwide, except for some small regions around Hawaii and the subtropical North Atlantic. The 90-percentile value of Rx1d-TC will decrease in the tropics as in the 50-percentile value, whereas it shows an increase in a region extending from the west coast of Mexico to the south of Japan. The distribution of the changes in the 90-percentile values of Rx1d-TC is similar to that of the frequency changes of category 4-5 TCs in this experiment (see Fig. $2 \mathrm{f}$ of Yoshida et al. 2017). Future weakening of the vertical shear of horizontal wind is considered a plausible reason for the intense TC changes in those regions.

The global mean change of the 90-percentile value of Rx1d-TC is negative (decreases in the future), but that of the 99-percentile value is positive (increases in the future). Except for the western tropical Pacific and the Indian Ocean where future change is negative, a large increase of an extremely intense Rx1d-TC is projected in the Northern Hemisphere subtropics (Fig. 3f). The coastal regions in East Asia including Japan, Taiwan, Hawaii, western Mexico, northern Arabian Sea, Madagascar, northwestern Australia, southeastern Brazil, northeastern America, and western North Africa are among the regions with increasing very rare extreme precipitation events associated with TCs.

Future changes in the 50-, 90-, and 99-percentile values of the Rxld-nTC are shown in Figs. 3g-i. They are similar to those of the Rx1d, but the regions with negative changes are narrower than those in the Rxld, because the reduction of TC frequency does not affect the Rx1d-nTC.

As Fig. 3 reveals, the sign of TC-associated Rx1d changes depends on the threshold percentile. Figure 5 shows the largest percentile value in each grid point at which future changes in Rxld and Rx1d-TC change their sign. Here, this threshold point is defined as the first percentile at which the future value becomes lower than the present-day value by searching backward from the maximum value. The threshold point is calculated for 900 years in 36 combinations of the six future experiments with different $\triangle \mathrm{SST}$ and six non-overlapping 900-year periods of the present-day experiment. The average values of 36 cases are shown in Fig. 5.

In mid- and high-latitudes, future Rx1d will increase even at less than the 10-percentile threshold. As
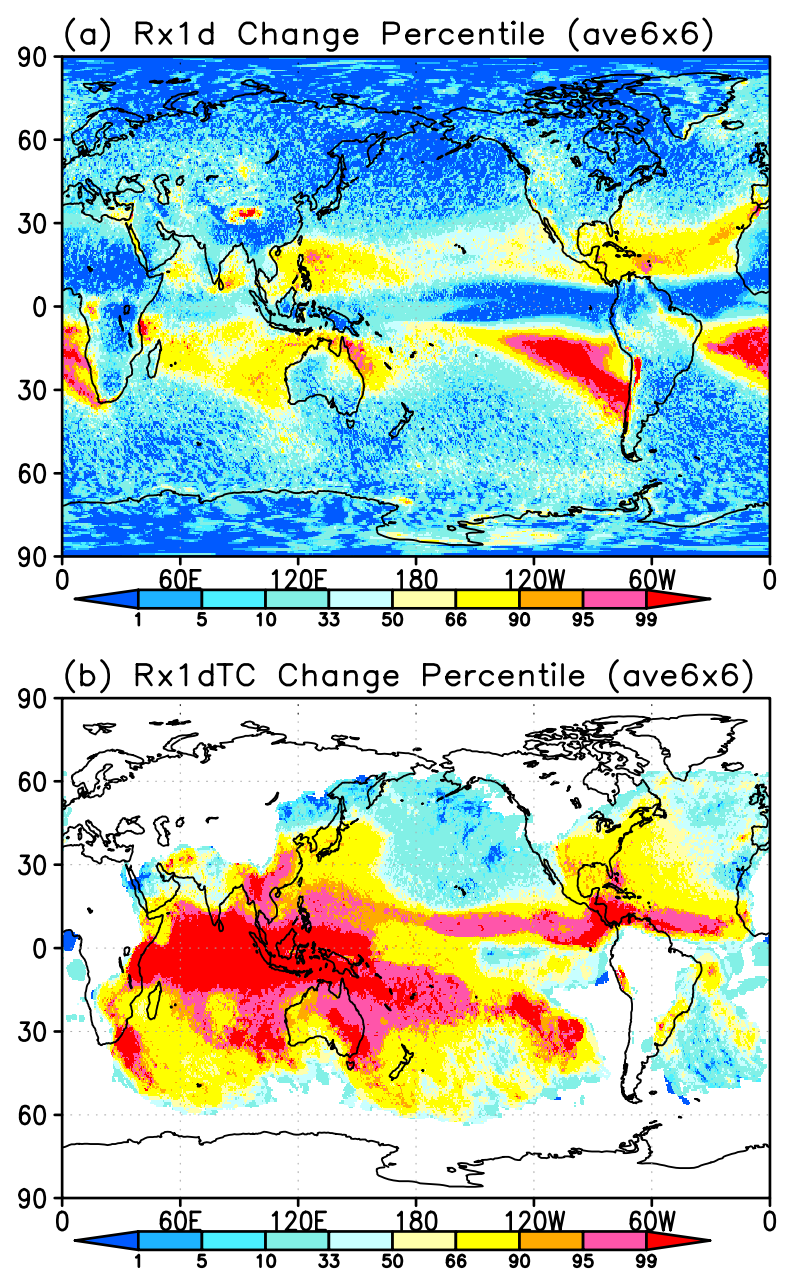

Fig. 5. Largest percentile value in each grid point at which future changes in (a) Rx1d and (b) Rx1d-TC change sign. These values are calculated for each experiment (different SST patterns) and then averaged.

shown in Fig. 5a, in most of the land areas, the threshold is found to be below 33-percentile. The Rx1d only above the 66-percentile will increase in the future in the area affected by TCs and in the subtropical oceanic dry areas in southeastern Pacific and southeastern Atlantic.

It is interesting to find that red color appears over the eastern Tibetan Plateau, where the largest Rxld in the future is less than that in the present (this spot can be seen in Fig. 3c). Kitoh and Arakawa (2016) investigated the future changes in the water budget in the eastern and western Tibetan Plateau simulated using the $20-\mathrm{km}$ mesh MRI-AGCM. They noted a projected 

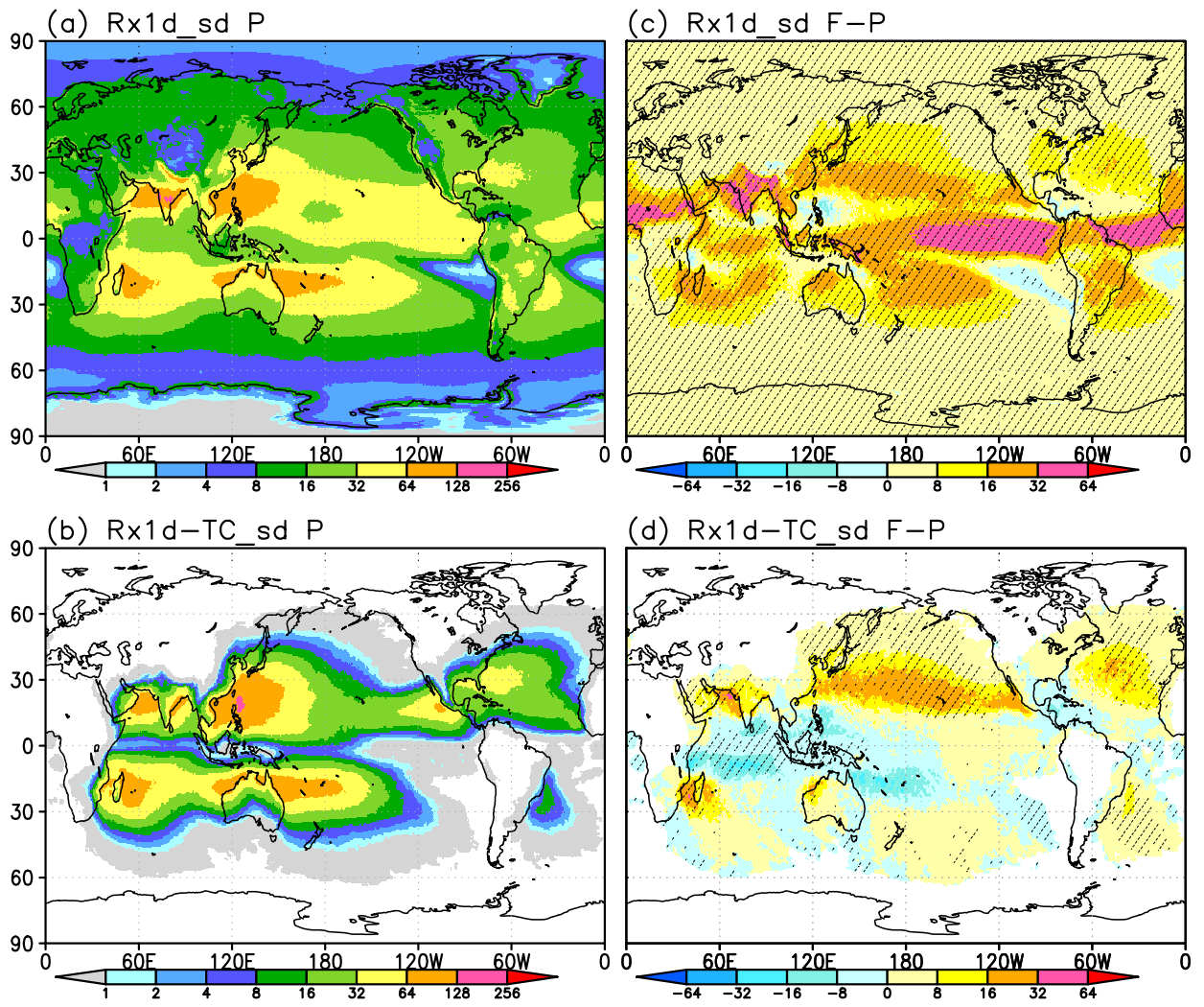

(d) Rx1d-TC_sd F-P

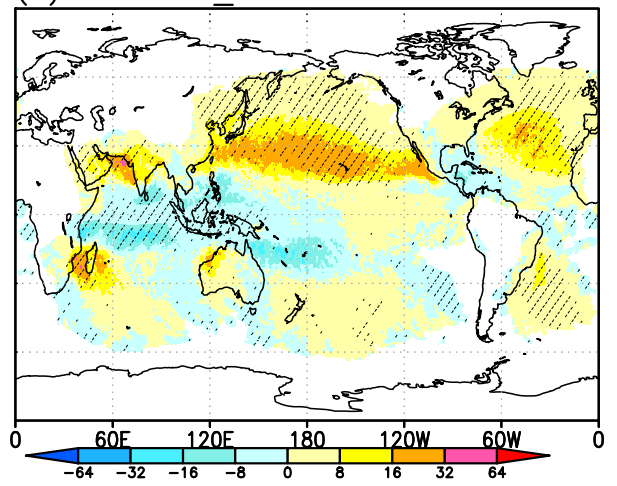

Fig. 6. (a) Interannual standard deviations of present-day Rx1d. (b) Similar to (a) but for Rx1d-TC. (c) Future changes (future minus present) of interannual standard deviations of Rx1d. (d) Similar to (c) but for Rx1d-TC. Unit is $\mathrm{mm}$. The hatches denote the areas where all six members of different $\triangle \mathrm{SST}$ pattern experiments have the same sign.

drying at the surface of the eastern Tibetan Plateau. The drying surface condition, which also occurs in the $60-\mathrm{km}$ model, may have resulted in least occurrence of extremely heavy precipitation in these areas in the future climate.

Figure $5 \mathrm{~b}$ reveals that the threshold percentile from negative to positive changes in Rx1d-TC is more than 50-percentile except around Hawaii, as already indicated in Fig. 3d. The threshold percentile is more than 80-percentile in tropical Indian and western Pacific regions, including East Asia around Japan and eastern China, and southeastern USA. In these regions, our model results suggest that extreme TC-associated precipitation once in 5 years will become more intense in warmer climate in the future.

Large changes in extreme precipitation would lead to changes in the interannual variability. Figures $6 \mathrm{a}$ and $6 \mathrm{~b}$ show the interannual standard deviations of the present-day Rx1d and Rx1d-TC, respectively. The distribution of the standard deviations of Rx1d-TC (Fig. 6b) is similar to that of Rx1d-TC (Fig. 2e). The coefficient of the variability (standard deviation divided by the mean) of Rx1d-TC is close to 1 around the main TC active regions. On the other hand, the standard deviations of Rx1d (Fig. 6a) are much smaller than Rx1d (Fig. 2d). Globally, the averaged coefficient of variability of Rx1d is about 0.5 . This is because variability of Rx1d-nTC is smaller than that of Rx1d owing to large variability of the TC occurrence. As Rx1d consists of Rx1d-TC and Rx1d-nTC, the coefficient of the variability of Rx1d becomes smaller than that of Rx1d-TC.

Figures $6 \mathrm{c}$ and $6 \mathrm{~d}$ show the future changes in interannual standard deviations of Rx1d and Rx1d-TC, respectively. The largest increase in Rxld variability is found in the equatorial Pacific. In this experiment, the same SST variability, such as El Niño and La Niña, is prescribed in the present as well as in the 
future. Moisture rich future atmosphere would result in large precipitation response to El Niño and La Niña (Kitoh and Endo 2016b). Other regions with increased Rxld variability include the Atlantic Ocean, India, and tropical Africa. Rx1d variability also increases in regions extending from Hawaii to the south of Japan where the interannual variability in Rx1d-TC also becomes larger in the future climate (Fig. 6d). This zone corresponds to where intense TCs will be more frequent in the future (Yoshida et al. 2017), and the 90- and 99-percentile values of Rx1d-TC are projected to increase (Figs. 3e, f).

\section{Summary and discussions}

A large ensemble experiment, i.e., 6,000 years for the present and 5,400 years for the future warmer world similar to the RCP8.5 scenario, is performed using the $60-\mathrm{km}$ mesh MRI-AGCM3.2. The present-day simulation consists of 100 ensemble members for a 60-year period (1951-2010), while the future simulation consists of 90 ensemble members for a 60 year period at the end of the 21 st century. The Rx1d will increase in the future world, except in the western North Pacific. Small changes or even reduction of Rx1d in these regions is mainly related to the projected decrease of the TC frequency in the future climate of this region. This result is qualitatively consistent with the previous findings of Kitoh and Endo (2016b) using the 20-km mesh MRI-AGCM3.2. Further findings are obtained thanks to the large ensemble size of this experiment. The interannual variability of Rxld increases in most of the western North Pacific areas. A reduction in the interannual variability of Rx1d is confined near the Philippines. Moreover, 90- and 99percentile values of Rx1d will increase in most parts of the world, implying an increasing risk of heavier rainfall events owing to global warming.

As we used the AGCM with fixed SST, one may concern about the effect of air-sea interaction on the results because it is widely known that ocean-atmosphere coupling process is essential in the western tropical Pacific at least for the seasonal prediction (Wang et al. 2005). Ogata et al. $(2015,2016)$ performed an experiment using the $60-\mathrm{km}$ mesh MRIAGCM3.2 to investigate the air-sea interaction effects through an AOGCM with flux adjustment. Necessary flux adjustment values are obtained by nudging the SST toward the present and future SST used in the AGCM experiment. Figure 7 shows the future changes in Rx1d and Rx1d-TC in this experiment, which is very similar to Figs. 3a and 3d, respectively, obtained using the AGCM without air-sea interaction. There-
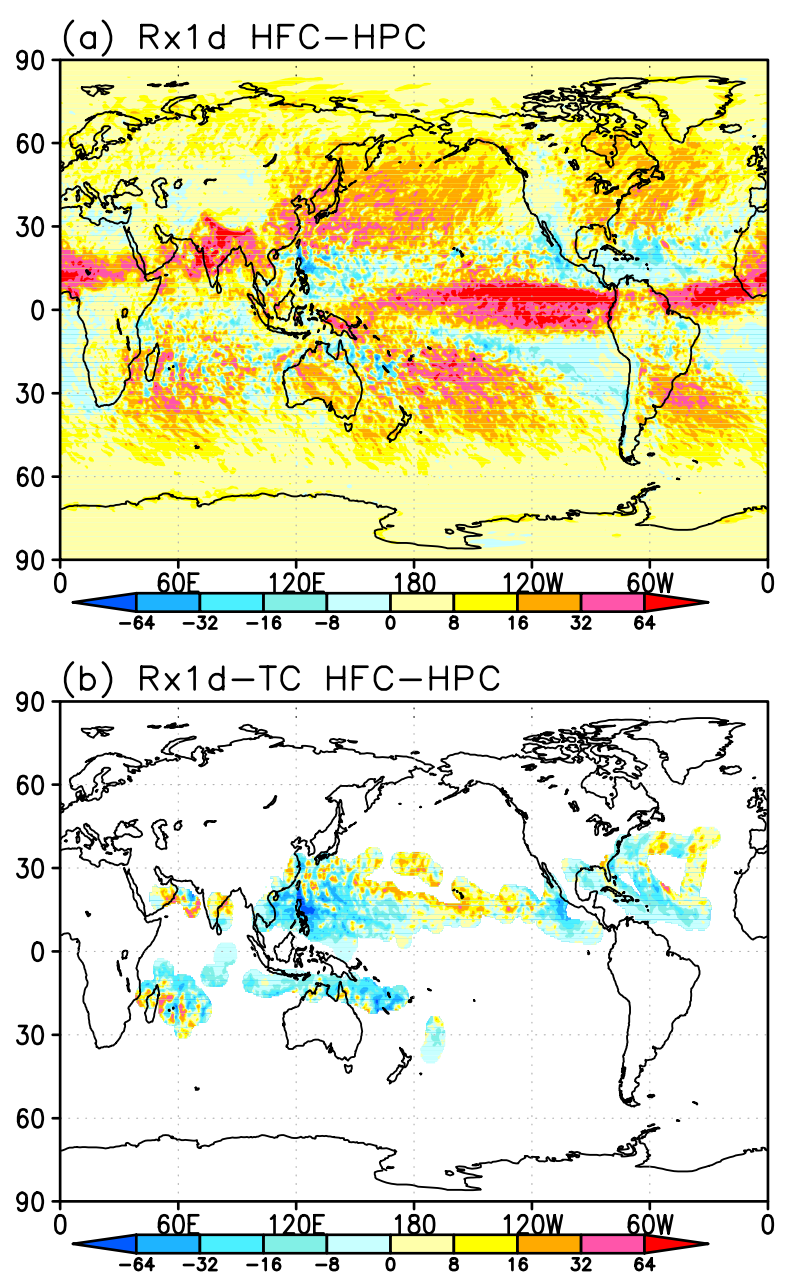

Fig. 7. Projected future changes (future minus present) of (a) Rx1d and (b) Rx1d-TC from the 60-km mesh MRI-AGCM with the effect of airsea interaction. Unit is $\mathrm{mm}$.

fore, changes in heavy precipitation are not largely affected by air-sea interaction, although the mean precipitation changes are greatly affected by inclusion of air-sea interaction (not shown). This result may be due to the fact that time scale of extreme precipitation, such as Rx1d, is very short. Ogata et al. $(2015,2016)$, however, found that the effect of air-sea coupling leads to more realistic TC distribution in a present-day climate simulation.

There are strength and weakness in our experiment (Mizuta et al. 2017). One of the strength of d4PDF is its high resolution. Although the resolution is coarser than the $20-\mathrm{km}$ model used by Kitoh and Endo (2016b) and others, this global 60-km mesh 
can still be grouped among high-resolution models in the literature, which can reproduce TCs to a certain extent. Large ensemble size $(6,000$ years for the present and 5,400 years for the future) is the largest advantage of this data set. The uncertainty of future changes in SST is also considered. There are some weaknesses. Compared with the $20-\mathrm{km}$ model version and observations, the strength of TCs and associated precipitation is underestimated. As already mentioned, the air-sea coupling is not included, which may affect some of the TC characteristics (Ogata et al. 2015, 2016). Moreover, the use of one particular model does not cover a full spectrum of uncertainty. To overcome the demerits of the d4PDF experiment, a multi-model approach is desirable. Multi-model high-resolution model experiments have started as the High Resolution Model Intercomparison Project (HighResMIP) (Haarsma et al. 2016), the results of which will be available in the near future.

\section{Acknowledgments}

This work was conducted under the Integrated Climate Model Advanced Research Program (TOUGOU) of the Ministry of Education, Culture, Sports, Science, and Technology (MEXT) of Japan. This study used d4PDF produced with the Earth Simulator jointly by science programs (SOUSEI, TOUGOU, SI-CAT, DIAS) of MEXT.

\section{References}

Chen, Y., E. E. Ebert, K. J. E. Walsh, and N. E. Davidson, 2013: Evaluation of TRMM 3B42 precipitation estimates of tropical cyclone rainfall using PACRAIN data. J. Geophys. Res., 118, 2184-2196.

Endo, H., A. Kitoh, T. Ose, R. Mizuta, and S. Kusunoki, 2012: Future changes and uncertainties in Asian precipitation simulated by multiphysics and multi-sea surface temperature ensemble experiments with highresolution Meteorological Research Institute atmospheric general circulation models (MRI-AGCMs). J. Geophys. Res., 117, D16118, doi:10.1029/2012JD 017874.

Endo, H., A. Kitoh, R. Mizuta, and M. Ishii, 2017: Future changes in precipitation extremes in East Asia and their uncertainty based on large ensemble simulations with a high-resolution AGCM. SOLA, 13, 7-12.

Haarsma, R. J., M. J. Roberts, P. L. Vidale, C. A. Senior, A. Bellucci, Q. Bao, P. Chang, S. Corti, N. S. Fučkar, V. Guemas, J. von Hardenberg, W. Hazeleger, C. Kodama, T. Koenigk, L. R. Leung, J. Lu, J.-J. Luo, J. Mao, M. S. Mizielinski, R. Mizuta, P. Nobre, M. Satoh, E. Scoccimarro, T. Semmler, J. Small, and J.-S. von Storch, 2016: High Resolution Model Inter- comparison Project (HighResMIP v1.0) for CMIP6. Geosci. Model Dev., 9, 4185-4208.

Hirahara, S., M. Ishii, and Y. Fukuda, 2014: Centennial-scale sea surface temperature analysis and its uncertainty. $J$. Climate, 27, 57-75.

Huffman, G. J., and D. T. Bolvin, 2009: GPCP one-degree daily precipitation data set documentation. NASA Goddard Space Flight Center, 25 pp. [Available at ftp://meso-a.gsfc.nasa.gov/pub/1dd-v1.1/1DD_v1.1_ doc.pdf.]

Huffman, G. J., R. F. Adler, D. T. Bolvin, G. Gu, E. J. Nelkin, K. P. Bowman, Y. Hong, E. F. Stocker, and D. B. Wolff, 2007: The TRMM Multisatellite Precipitation Analysis (TMPA): Quasi-global, multiyear, combined-sensor precipitation estimates at finer scale. J. Hydrometeor, 8, 38-55.

IPCC, 2012: Managing the Risks of Extreme Events and Disasters to Advance Climate Change Adaptation. A Special Report of Working Groups I and II of the Intergovernmental Panel on Climate Change. Field, C. B., V. Barros, T. F. Stocker, D. Qin, D. J. Dokken, K. L. Ebi, M. D. Mastrandrea, K. J. Mach, G.-K. Plattner, S. K. Allen, M. Tignor, and P. M. Midgley (eds.), Cambridge University Press, Cambridge, UK, and New York, NY, USA, $582 \mathrm{pp}$.

Joyce, R. J., J. E. Janowiak, P. A. Arkin, and P. Xie, 2004: CMORPH: A method that produces global precipitation estimates from passive microwave and infrared data at high spatial and temporal resolution. J. Hydrometeor., 5, 487-503.

Kamahori, H., 2012: Mean features of tropical cyclone precipitation from TRMM/3B42. SOLA, 8, 17-20.

Kitoh, A., and O. Arakawa, 2016: Reduction in the eastwest contrast in water budget over the Tibetan Plateau under a future climate. Hydrol. Res. Lett., 10, 113118.

Kitoh, A., and H. Endo, 2016a: Changes in precipitation extremes projected by a $20-\mathrm{km}$ mesh global atmospheric model. Weather. Climate Extremes, 11, 41-52.

Kitoh, A., and H. Endo, 2016b: Future changes in rainfall extremes associated with El Niño projected by a global 20-km mesh atmospheric model. SOLA, 12A, $1-6$.

Kitoh, A., T. Ose, K. Kurihara, S. Kusunoki, M. Sugi, and KAKUSHIN Team-3 Modeling Group, 2009: Projection of changes in future weather extremes using super-high-resolution global and regional atmospheric models in the KAKUSHIN Program: Results of preliminary experiments. Hydrol. Res. Lett., 3, 49-53.

Kitoh, A., T. Ose, and I. Takayabu, 2016: Dynamical downscaling for climate projection with high-resolution MRI AGCM-RCM. J. Meteor. Soc. Japan, 94A, 1-16.

Knapp, K. R., M. C. Kruk, D. H. Levinson, H. J. Diamond, and C. J. Neumann, 2010: The International Best Track Archive for Climate Stewardship (IBTrACS), Unifying tropical cyclone best track data. Bull. Amer. 
Meteor. Soc., 91, 363-376.

Kusunoki, S., 2016: Is the global atmospheric model MRIAGCM3.2 better than the CMIP5 atmospheric models in simulating precipitation over East Asia? Climate Dyn., 51, 4489-4510.

Kusunoki, S., 2017: Future changes in global precipitation projected by the atmospheric model MRI-AGCM3.2H with a 60-km size. Atmosphere, 8, 93, doi:10.3390/ atmos8050093.

Kusunoki, S., and R. Mizuta, 2013: Changes in precipitation intensity over East Asia during the 20th and 21st centuries simulated by a global atmospheric model with a $60 \mathrm{~km}$ grid size. J. Geophys. Res., 118, 11007-11016.

Matsueda, M., and H. Endo, 2017: The robustness of future changes in Northern Hemisphere blocking: A large ensemble projection with multiple sea surface temperature patterns. Geophys. Res. Lett., 44, 5156-5166.

Mizuta, R., H. Yoshimura, H. Murakami, M. Matsueda, H. Endo, T. Ose, K. Kamiguchi, M. Hosaka, M. Sugi, S. Yukimoto, S. Kusunoki, and A. Kitoh, 2012: Climate simulations using MRI-AGCM3.2 with 20-km grid. $J$. Meteor. Soc. Japan, 90A, 233-258.

Mizuta, R., A. Murata, M. Ishii, H. Shiogama, K. Hibino, N. Mori, O. Arakawa, Y. Imada, K. Yoshida, T. Aoyagi, H. Kawase, M. Mori, Y. Okada, T. Shimura, T. Nagatomo, M. Ikeda, H. Endo, M. Nosaka, M. Arai, C. Takahashi, K. Tanaka, T. Takemi, Y. Tachikawa, K. Temur, Y. Kamae, M. Watanabe, H. Sasaki, A. Kitoh, I. Takayabu, E. Nakakita, and M. Kimoto, 2017: Over 5,000 years of ensemble future climate simulations by $60-\mathrm{km}$ global and $20-\mathrm{km}$ regional atmospheric models. Bull. Amer. Meteor. Soc., 98, 1383-1398.

Murakami, H., Y. Wang, H. Yoshimura, R. Mizuta, M. Sugi, E. Shindo, Y. Adachi, S. Yukimoto, M. Hosaka, S. Kusunoki, T. Ose, and A. Kitoh, 2012a: Future changes in tropical cyclone activity projected by the new high-resolution MRI-AGCM. J. Climate, 25, 32373260 .

Murakami, H., R. Mizuta, and E. Shindo, 2012b: Future changes in tropical cyclone activity projected by multi-physics and multi-SST ensemble experiments using the 60-km-mesh MRI-AGCM. Climate Dyn., 39, 2569-2584.

Ogata, T., R. Mizuta, Y. Adachi, H. Murakami, and T. Ose, 2015: Effect of air-sea coupling on the frequency distribution of intense tropical cyclones over the northwestern Pacific. Geophys. Res. Lett., 42, 1041510421.

Ogata, T., R. Mizuta, Y. Adachi, H. Murakami, and T. Ose, 2016: Atmosphere-ocean coupling effect on intense tropical cyclone distribution and its future change with 60 km-AOGCM. Sci. Rep., 6, 29800, doi:10.1038/ srep29800.

O'Gorman, P. A., 2012: Sensitivity of tropical precipitation extremes to climate change. Nat. Geosci., 5, 697-700.

Ose, T., and O. Arakawa, 2011: Uncertainty of future precip- itation change due to global warming associated with sea surface temperature change in the tropical Pacific. J. Meteor. Soc. Japan, 89, 539-552.

Scoccimarro, E., S. Gualdi, A. Bellucci, M. Zampieri, and A. Navarra, 2013: Heavy precipitation events in a warmer climate: Results from CMIP5 models. $J$. Climate, 26, 7902-7911.

Sillmann, J., V. V. Kharin, X. Zhang, F. W. Zwiers, and D. Bronaugh, 2013a: Climate extremes indices in the CMIP5 multimodel ensemble: Part 1. Model evaluation in the present climate. J. Geophys. Res., 118, 1716-1733.

Sillmann, J., V. V. Kharin, F. W. Zwiers, X. Zhang, and D. Bronaugh, 2013b: Climate extremes indices in the CMIP5 multimodel ensemble: Part 2. Future climate projections. J. Geophys. Res., 118, 2473-2493.

Sorooshian, S., K.-L. Hsu, X. Gao, H. V. Gupta, B. Iman, and D. Braithwaite, 2000: Evaluation of PERSIANN system satellite-based estimates of tropical rainfall. Bull. Amer. Meteor. Soc., 81, 2035-2046.

Sugi, M., and J. Yoshimura, 2012: Decreasing trend of tropical cyclone frequency in 228-year high-resolution AGCM simulations. Geophys. Res. Lett., 39, L19805, doi:10.1029/2012GL053360.

Taylor, K. E., R. J. Stouffer, and G. A. Meehl, 2012: An overview of CMIP5 and the experiment design. Bull. Amer. Meteor. Soc., 93, 485-498.

Tebaldi, C., K. Hayhoe, J. M. Arblaster, and G. A. Meehl, 2006: Going to extremes: An intercomparison of model-simulated historical and future changes in extreme events. Climate Change, 79, 185-211.

Ushio, T., K. Sasashige, T. Kubota, S. Shige, K. Okamoto, K. Aonashi, T. Inoue, N. Takahashi, T. Iguchi, M. Kachi, R. Oki, T. Morimoto, and Z. Kawasaki, 2009: A Kalman filter approach to the Global Satellite Mapping of Precipitation (GSMaP) from combined passive microwave and infrared radiometric data. $J$. Meteor. Soc. Japan, 87A, 137-151.

Wang, B., Q. Ding, X. Fu, I.-S. Kang, K. Jin, J. Shukla, and F. Doblas-Reyes, 2005: Fundamental challenge in simulation and prediction of summer monsoon rainfall. Geophys. Res. Lett., 32, L15711, doi:10.1029/2005GL 022734.

Xie, S.-P., C. Deser, G. A. Vecchi, J. Ma, H. Teng, and A. T. Wittenberg, 2010: Global warming pattern formation: Sea surface temperature and rainfall. J. Climate, 23, 966-986.

Yoshida, K., M. Sugi, R. Mizuta, H. Murakami, and M. Ishii, 2017: Future changes in tropical cyclone activity in high-resolution large-ensemble simulations. Geophys. Res. Lett., 44, 9910-9917.

Yoshimura, H., R. Mizuta, and H. Murakami, 2015: A spectral cumulus parameterization scheme interpolating between two convective updrafts with semi-Lagrangian calculation of transport by compensatory subsidence. Mon. Wea. Rev., 143, 597-621. 